\title{
Recurrent Liver Carcinoma
}

National Cancer Institute

\section{Source}

National Cancer Institute. Recurrent Liver Carcinoma. NCI Thesaurus. Code C7110.

The reemergence of liver carcinoma after a period of remission. 